Çukurova Üniversitesi Mühendislik Mimarlık Fakültesi Dergisi, 34(1), ss. 233-243, Mart 2019

Çukurova University Journal of the Faculty of Engineering and Architecture, 34(1), pp. 233-243, March 2019

\title{
Yozgat Sarıkaya Termal Roma Hamamı'nda Kullanılan Doğal Yapı Taşları ve Mühendislik Özellikleri
}

\author{
Zeynel BAŞIBÜYÜK ${ }^{* 1}$, Gökhan EKİNCIOOĞLU ${ }^{2}$, Mehmet Mustafa ÖNAL ${ }^{3}$ \\ ${ }^{1}$ Ahi Evran Üniversitesi, Mühendislik Mimarlık Fakültesi, Jeoloji Mühendisliği Bölümü, Kirşehir \\ ${ }^{2}$ Ahi Evran Üniversitesi, Kaman MYO, Madencilik ve Maden Çıkarma Bölümü, Kırşehir \\ ${ }^{3}$ Ahi Evran Üniversitesi, Mühendislik Mimarlık Fakültesi, İnşaat Mühendisliği Bölümü, Kırşshir
}

Geliş tarihi: 07.01.2019 Kabul tarihi: 27.03.2019

$\ddot{\mathbf{O} z}$

Doğaltaş, geçmişten günümüze insanoğlunun yaşamında alet yapımı, mimari, sanat gibi birçok alanda yer almıştır. Yozgat ili Sarıkaya ilçe merkezinde bulunan ve doğaltaşın Anadolu'da mimari eser olarak kullanılmış örneklerinden biri olan Sarıkaya Termal Roma Hamamı, MS 2. yüzyılın ortalarında inşa edilmiştir. Termal Roma Hamamının günümüze kadar korunarak gelmiş olan batı cephesinde, havuzlarında ve yer döşemelerinde mermer, sadece temel seviyeleri korunarak gelmiş iç kısım duvarlarında ve havuz basamaklarında ise kireçtaşı kullanılmıştır.

Yapının inşasında kullanılan mermerlerin, ilçe merkezinin yaklaşı $1 \mathrm{~km}$ güneyinde bulunan Paleozoyik yaşlı Kırşehir Masifi içerisindeki Bozçaldağ Formasyonuna ait metamorfik kayaçlar içerisindeki mermer seviyelerinden, kireçtaşlarının ise ilçe merkezinin birkaç km kuzey-kuzeydoğusundaki Orta MiyosenPliyosen yaşlı sedimanter kayaçlar içerisinde bulunan kireçtaşı seviyelerinden alındığı düşünülmektedir. Sarıkaya Termal Roma Hamamının inşasında kullanıldığı düşünülen mermer ve kireçtaşı birimlerinden alınan numunelerin mühendislik özellikleri, ilgili TS EN ve ISRM standartlarına göre belirlenmiştir. Çalışma alanındaki kireçtaşları porozite, sertlik, basınç dayanımı, yüzey aşınma dayanımı gibi mühendislik özellikleri açısından mermerlere göre daha dayanıksız olmakla birlikte, olasılıkla, düşük maliyet, kolay işlenebilirlik, ısı yalıtımı ve pürüzlülük gibi özellikleri nedeni ile yapıda kullanılmıştır. Sarıkaya Termal Roma Hamamı'nda ilerleyen dönemlerde gerçekleştirilebilecek restorasyon çalışmaları kapsamında kullanılacak doğaltaşların doğru kaynaklardan seçimi açısından bu ve benzeri çalışmalar yol gösterici olacaktır.

Anahtar Kelimeler: Roma hamamı, Mermer, Kireçtaşı, Fiziksel ve mekanik özellikler, Yozgat

\section{Natural Building Stones Used in Yozgat Sarikaya Thermal Roman Bath and Engineering Specifications}

\begin{abstract}
Natural stone has taken place in many areas such as tool making, architecture and art in the life of mankind from past to present. The Sarkaya Thermal Roman Bath located in the district center of Sarıkaya in Yozgat Province, and being one of the representations of natural stone as an architectural
\end{abstract}

*Sorumlu yazar (Corresponding author): Zeynel BAŞIBÜYÜK, zbasibuyuk@ahievran.edu.tr 
work of art in Anatolia, was built in mid- $2^{\text {nd }}$ century AD. In the western facade, pools and flooring of the Thermal Roman Bath, preserved to date, marble was used; while limestone was used in interior walls, preserved only at base level, and pool stairs.

Of the natural building stones applied in the construction, it is assumed that marble was extracted from the marble layers of the metamorphic rocks in Bozçaldağ Formation within the Paleozoic-aged Kırşehir Massive, which is located about $1 \mathrm{~km}$ south of the district center; and limestone was supplied from the limestone layers within the sedimentary rocks of mid-Miocene-Pliocene period, that are located a few kilometers north-northeast off the district center. Engineering specifications of marble and limestone units believed to have been applied in the construction of Sarkkaya Thermal Roman Bath have been identified using the related TS EN and ISRM standards. Although limestone in the study area is less durable compared to marble in terms of engineering properties such as porosity, rigidity, and compression and surface abrasion resistance; probably, they were used in construction for their specifications such as low cost, workability, heat insulation and asperity. This study and similar ones will be guiding in terms of selection of natural stones from appropriate resources to be used in scope of potential restoration efforts in the Sarıkaya Thermal Roman Bath in future.

Keywords: Roman bath, Marble, Limestone, Physical and mechanical properties, Yozgat

\section{GİRIŞ}

Doğaltaşın sert hava koşullarına dayanıklı olması, taşıyıc1 gücünün fazla olması ve doğada bol miktarda bulunması, yüzyıllar boyunca mimaride önemli bir yapı malzemesi olarak kullanılmasını sağlamıştır. Günümüzde zemin döşemelerinde, iç ve dış kaplamada, anıt yapılarda ve mezarcılıkta, süs eşyası yapımında ve diğer alanlarda yaygın olarak kullanılmaktadır. Anadolu uygarlıkları, çağlar boyunca kültürel, siyasal ve toplumsal yapılarını, bu topraklardan çıkardıkları doğal taşlarla yaptıkları anıtlara, külliyelere, medreselere, binalara kazımışlardır [1]. İnsanlık tarihi boyunca gücü, zenginliği, iktidarı simgeleyen büyük anıtsal yapılar, heykeller ve binalar doğal taşlardan yapılmıştır. Doğaltaşların geçmişten gelen bu ihtişamı, günümüzde de bina ve yapıtlarımızda kendini göstermektedir. Taşın tarihini incelemek ve insan yaşamındaki yerini ortaya koymak farklı disiplinlerin bir arada çalışmasını gerektirmektedir. Yer bilimleri ve arkeoloji başta olmak üzere mimari, mühendislik, kültürel antropoloji, sanat tarihi gibi disiplinlerde taşların işleniş ve kullanılış biçimleri üzerine çalışmalar ortaya koyulmuştur.

Binlerce yıl önce yapılan ve günümüze kadar ulaşabilen anıtsal mimari yapıların hammaddesi taştır. Taş, yalnızca mimaride değil alet yapımında da en önemli maddelerden biri olagelmiştir [2-4]. Arkeolojik araştırmalar sonucunda insanlık tarihi ile ilgili yapılmış olan dönemsel ayrım taş, tunç ve demir ayrımıdır. İlk olarak 1816 yılında Danimarkalı Thomsen tarafindan yapılan bu ayrım günümüzde de hala kabul görmektedir [5]. Bunun nedeni, insanlık tarihini başlatan olayın ilk taş alet üretim teknolojisi olmasıdır. $\mathrm{Bu}$ ayrıma göre insanlık tarihini şekillendiren aşamalar Paleo-litik Çağ (Eski Taş Çağı), Mezo-litik (Orta Taş Çağı) ve Neo-litik Çağ (Yeni Taş Çağı) olarak gelişmiştir. Thomsen'in Üç Çağ sistemi, sınıflandırmaya ve veri içerisindeki modelleri gözlemleyerek oluşturulan deneysel ve tümevarımsal araştırmaya yönelik güzel bir çalışmadır [6] ve arkeolojik kronolojinin temelini oluşturmaktadır [7].

Bugün ayakta kalan en büyük tarihi yapılar taştan yapılmıştır (Mısır Piramitleri, Stonehenge, Yunan Akropolleri, Roma tiyatroları, Osmanlı çeşme ve camileri gibi). Aynı zamanda iki tanesi ülkemizde bulunan dünyanın yedi harikasından Artemis Tapınağı (bütünüyle mermerden yapılmıştır) ve Halikarnas Mozolesi de tarihteki taş kullanımının en popüler örnekleri arasında yer almaktadır [8]. Söz konusu yapılar yüzlerce kilometre uzaktan getirilerek yıllarca süren uğraşlar sonucu inşa edilmişlerdir [9]. 
Arkeolojik veriler uzak mesafelerden getirilen taşlarla inşa edilen yapıları belgelemiştir. Neolitik Çă̆ itibarı ile obsidyen ve çakmaktaşından yapılan el aletlerinin takas yoluyla ticari bir ürün olarak kullanıldığı $[10,11]$ yine kaya tuzunun ticari bir ürüne dönüştüğü bilinmektedir [12]. Mimari amaçlarla da uzun mesafelerden taş taşındığı bilinmektedir. Örneğin Güney Mezopotamya'da (günümüzdeki Warka kentinde) yer alan eski Uruk kentinde yapılan çalışmalarda kireçtaşı kullanılarak yapılmış olan ve arkeologların "Beyaz Tapınak" olarak adlandırdıkları bir yap1 bulunmaktadır. Sümerlerin ana tanrıçası İnanna'ya ithaf edilerek MÖ 3200-3000 civarında inşa edilen söz konusu tapınak yapısında kullanilan kireçtaşlarının bölgede bulunmuyor olması farklı bir yerden ithal edildiği şeklinde yorumlanmıştır. Firat Nehri'ne $12 \mathrm{~km}$ mesafede bulunan tapınak yapısı büyük olasılıkla nehir yoluyla Kuzey Mezopotamya'dan taşınan taşlarla inşa edilmiştir. Alanda yapılan kazılarda mermerden yapılmış ve yine tanrıça İnanna'nın tasvir edildiği düşünülen bir heykel başı da ele geçmiştir. Mimaride daha ziyade pişmiş toprak tuğla kullanan Sümerlilerin görece değerli olan taşları heykel yapımında kullanması, heykellerin de çoğunlukla (az bulunmasından kaynaklı olarak) yalnızca baş kısmının taştan oluşturulması, taşa verilen değerin birer kanıtıdır [13].

Taşın insan hayatındaki konumu aynı zamanda bilimden sanata kadar farklı yansımalar yapmıştır. Doğaltaş, el aleti, mücevher ve mimari amaçların dışında kimyasal amaçlarla da kullanılmıştır. Daha Neolitik Çağ itibarı ile kireçtaşı ve alçı taşının toz haline getirilip suyla tepkimeye sokularak kullanılmaya başladığı bilinmektedir [9]. Farrelly'e göre mimarlık ve sanat tarihi, aynı zamanda doğal taşların kullanım tarihidir [14]. Bütün ünlü yapıların taşlarının nerelerden getirildiği belgelidir. Yapılara yenileme ve ya bakım gerektiğinde, orijinal taş ocaklarının kullanılması önerilmektedir [15]. Çünkü zaman içinde yapı ünlenirken, onu görkemli kılan taşlar daha çok aranır olmakta, böylece eserler gibi orada kullanılan taşlar da "ulusal değer" halini almaktadır [16].
Mimari restorasyonun temel ilkelerini belirleyen Uluslararası Anitlar ve Sitler Konseyi'nin (ICOMOS-International Council on Monuments and Sites) 1964 tarihli Venedik Tüzüğü’ne göre mimari onarım sırasında yapının inşa edildiği yapıtaşına uygun malzeme seçilmesi esastır [17]. İnsan yaşamı ile alakalı bütün doğal süreçlerin incelenmesi Kültürel Jeoloji kapsamındadır [18]. Bu tanım Farrelly'nin "mimarlık tarihi doğal taş kullanım tarihidir" görüşü ile birleştirildiğinde [14], doğal yapı taşlarının kültürel jeolojideki yerinin büyüklüğü ortaya çıkmaktadır. Doğal taşlardan ileri gelen özellik ve güzellikler, arkeolog ve sanat tarihçilerin olduğu kadar yer bilimcilerin de sorumluluğundadır $[15,19]$. Sarıkaya Termal Roma Hamamı'nın gelecekte restorasyonunun yapılması planlandığında orijinalinde kullanılan doğal yapı taşlarının kullanılması oldukça önemlidir. $\mathrm{Bu}$ nedenle bu çalışma ile ortaya çıkarılan bulgular önemli olacak ve bu restorasyon çalışmalarında referans alınabilecektir.

\section{SARIKAYA TERMAL ROMA HAMAMI'NIN MIMARI ÖZELLÍKLERİ}

Bulunduğu yöredeki doğal yapı taşlarından inşa edilmiş Sarıkaya Termal Roma Hamamı, kısmen korunmuş halde olup, günümüzde mermerden yapılmış ön cephe, havuzlar ve iç bölmelerin temel seviyeleri haricindeki diğer seviyeleri tahrip olmuştur (Şekil 1a ve b).

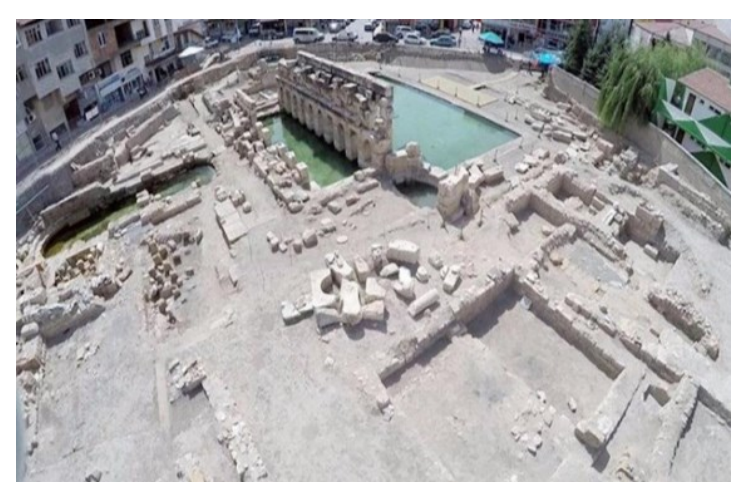

Şekil 1a. Sarıkaya Termal Roma Hamamı'nın havadan görünümü [20] 


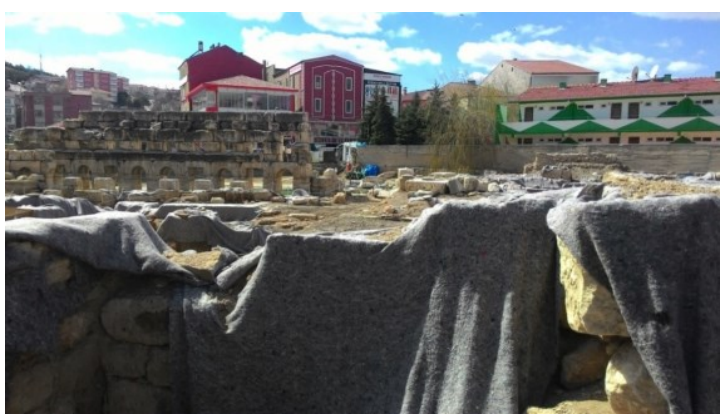

Şekil 1b. Sarıkaya Termal Roma Hamamı iç duvar temel seviyeleri

Sarıkaya Termal Roma Hamamı, Roma hamam mimarisinin Orta Anadolu'da görülen nadir yapılarından biridir. Hamamın ortaya çıkarılması için Yozgat Müzesi Müdürlüğü'nce 2010-2015 yıllarında kazı çalışmaları yapılmıştır. KuzeyGüney doğrultulu inşa edilen yapının günümüze kadar korunan en önemli kısmı batı cephesi olup, söz konusu cephe, yaklaşık 4,5 metre yükseklikte, iki katl, her katında onar kemer bulunan bir bölümdür (Şekil 2a ve b). Kuzey-güney uçlarında yarım daire planlı iki havuzcuk, önünde büyük termal havuz, cephe gerisinde iç havuz ve bunun doğusunda üçüncü bir havuz bulunmaktadır $[21,22]$.

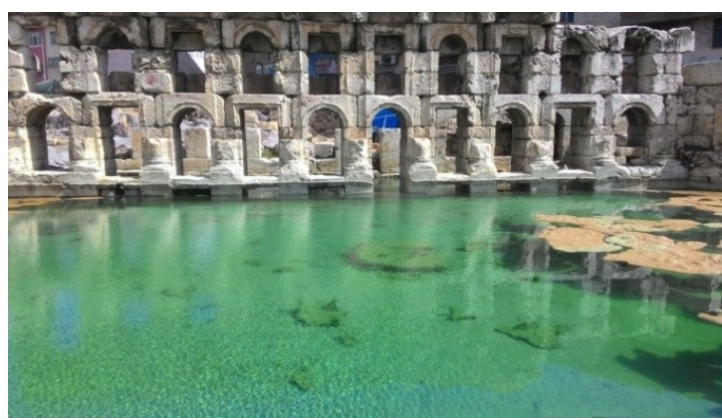

Şekil 2a. Sarıkaya Termal Roma Hamamı batı cephesi büyük havuz (natatio) dışından görünüm [22]

Önceki çalışmalarda bölgenin ve ilk Tunç Çă̆ı'ndan (MÖ 3200-2600) itibaren kesintisiz bir yerleşim alanı olduğu belirtilmektedir. Antik dönem haritalarında Kayseri ve Yozgat arasında kalan bu alanın "Aqua Sarvenae" olarak adlandırıldığı Roma dönemindeki adının ise
"Therma Basilica" olduğu bilinmektedir. Bölgede hâlihazırda var olan termal su kaynağının hamam içerisinde kullanıldığı ve aynı zamanda taban 1sıtmasında da kısmen faydalanıldığ 1 yapılan çalışmalarla ortaya konmuştur [22,23].

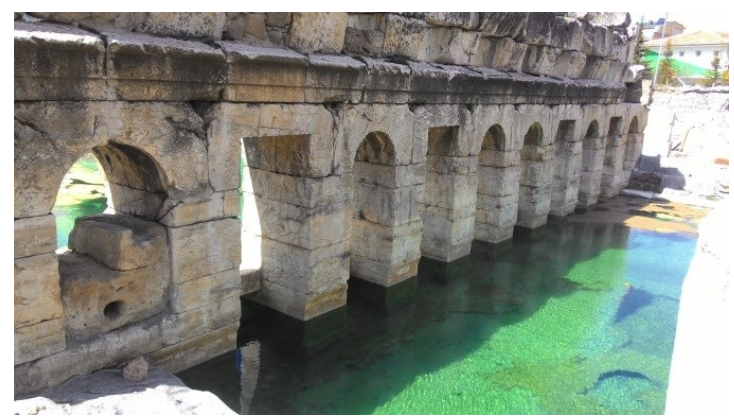

Şekil 2b. Sarıkaya Termal Roma Hamamı batı cephesi büyük havuz (natatio) içinden görünüm [22]

MS Roma dönemi terminolojisiyle değerlendirildiğinde, kaplıca ve hamam yapıları içerisinde bulunan bölümler sırasıyla, giriş/ soyunmalık (apodyterium), soğukluk (frigidarium), llıklık (tepidarium), sicaklık (caldarium), terleme yeri (laconicum), yüzme havuzu (natatio) gibi ana bölümlerden oluşmaktadır [24,25]. Roma hamamlarının taban isitmasinda "praefurnium" adlı bir ocak yakılır ve ateşin dumanının "hypocaus" adlı bölümden sirkülasyonu ile taban 1sıtması sağlanırdı. Sarıkaya hamamında ise sıra dışı olarak taban 1sıtması için açılan "hypocaust" adlı sisteme duman yerine sıcak su verilmiştir. Roma hamamlarında genellikle tabanda "hypocaustu" oluşturmak amaciyla pişmiş toprak tuğlalarla örülen "suspensura" adlı dikmeler bulunmaktaydı. Sarıkaya hamamında yine farklı olarak "suspensura" kısmında traverten kayaçlar kullanılmıştır [22].

Roma hamamlarında görsellik ön planda tutulmaktaydı. Hamam yapısının dış cephesinin görkemli inşasına karşın iç mekânda standart bir Roma hamamında bulunması beklenen mozaik döşemeler, heykeller veya özenli yapılmış çörtenler gibi unsurlar henüz ortaya çıkarılmamıştır. Ayrıca hamam yapısının batı cephesi kısmen sağlam vaziyette ayakta kalırken diğer cepheleri aynı oranda korunmamıştır [22]. 
Hamam yapısının ana yapı malzemeleri kısmen korunarak günümüze ulaşmışsa da duvar ve tabanda kaplama olarak kullanılan kısımlar günümüze ulaşmamış durumdadır. Bunun ana sebebi olasılıkla hamamın ișlevi bittikten sonra söz konusu malzemelerin sökülerek devşirme olarak kullanılmış olmasıdır. Hamamda yürütülen kazilara devam edilmesi durumunda daha fazla bilgi edinilmesi olasıdır.

\section{MATERYAL VE METOT}

Sarıkaya Termal Roma Hamamı'nın inşasında kullanılan hammaddenin kaynağının saptanması amacıyla Sarıkaya ve çevresinde jeolojik arazi çalışmaları yapılmış ve mimaride kullanılan doğal taşların muhtemel kaynakları tespit edilmiştir. Bu bölgelerden fiziko-mekanik analizlerin gerçekleştirilmesinde kullanılacak örnek alımları gerçekleştirilmiştir. Araziden alınan numunelerin ağırlıkça su emme (ASE) (TS EN 13755) [26], birim hacim ağırlık (BHA), özgül ağırlık (ÖA), toplam porozite (TP) (TS EN 1936) [27], böhme yüzey aşınma (BYA) (TS EN 14157) [28], Shore sertlik (SH) (ISRM (1981) [29] ve tek eksenli basınç dayanımı (TEBD) (TS EN 1926) [30] gibi fiziksel ve mekanik özellikleri ilgili standartlara göre belirlenmiştir.

\section{BÖLGENİN JEOLOJIKK YAPISI}

İnceleme sahasının temelini Paleozoyik yaşlı kalkşist, mikaşist, kuvars şist, gnays, kuvarsit ve mermerden oluşan Kırşehir Masifine ait Gümüşler, Kabaktepe ve Bozçaldağ Formasyonları oluşturmaktadır [31] (Şekil 3). Sarıkaya Termal Roma Hamamı'nın ana yapısını oluşturan mermerler, ilçenin birkaç kilometre güneyinde mostra veren masif görünümlü, birbirini kesen kırık çatlak düzlemleri içeren, orta-iri kristalli mermerlerden oluşan Bozçaldağ Formasyonundan alınmıştır (Şekil 4a,4b). Bu birimlerin üzerine uyumsuz olarak Alt-Orta Eosen yaşlı karasal çakıltaş1, kumtaş1 ve kireçtaşı birimlerinden oluşan Baraklı Formasyonu ile çakıltaşı, kumtaşı, kireçtaşı ve çamurtaşı birimlerinden oluşan Çayraz Formasyonu gelmektedir. $\mathrm{Bu}$ birimler üzerinde Orta Miyosen-Pliyosen yaşlı ayrılmamış karasal çökeller içeren İç Anadolu Grubu, Ürgüp Formasyonuna ait sar1-pembe ignimbiritlerden oluşan Tahar İgnimbirit Üyesi ve gölsel kireçtaşlarından oluşan Kozaklı Kireçtaşı Üyesi gelmektedir [31]. Sarıkaya Termal Roma Hamamı'nın temelinde, iç duvarlarında ve kanallarında kullanılan kumlu-çakıllı kireçtaşları ilçenin birkaç kilometre kuzeyinde bulunan gözenekli, genellikle metamorfik kökenli kumçakıl boyu kırıntı içeren, yaklaşık 5 metre kalınlığa kadar ulaşan (Şekil 5a), kirli beyaz-sarımsı renkli, kumlu-çakıllı gölsel kireçtaşlarından oluşan Kozaklı Kireçtaşı Üyesi'nden alınmıştır [22] (Şekil 5b). En üstte tüm birimleri uyumsuzlukla Kuvaterner yaşlı alüvyon örtü örtmektedir.
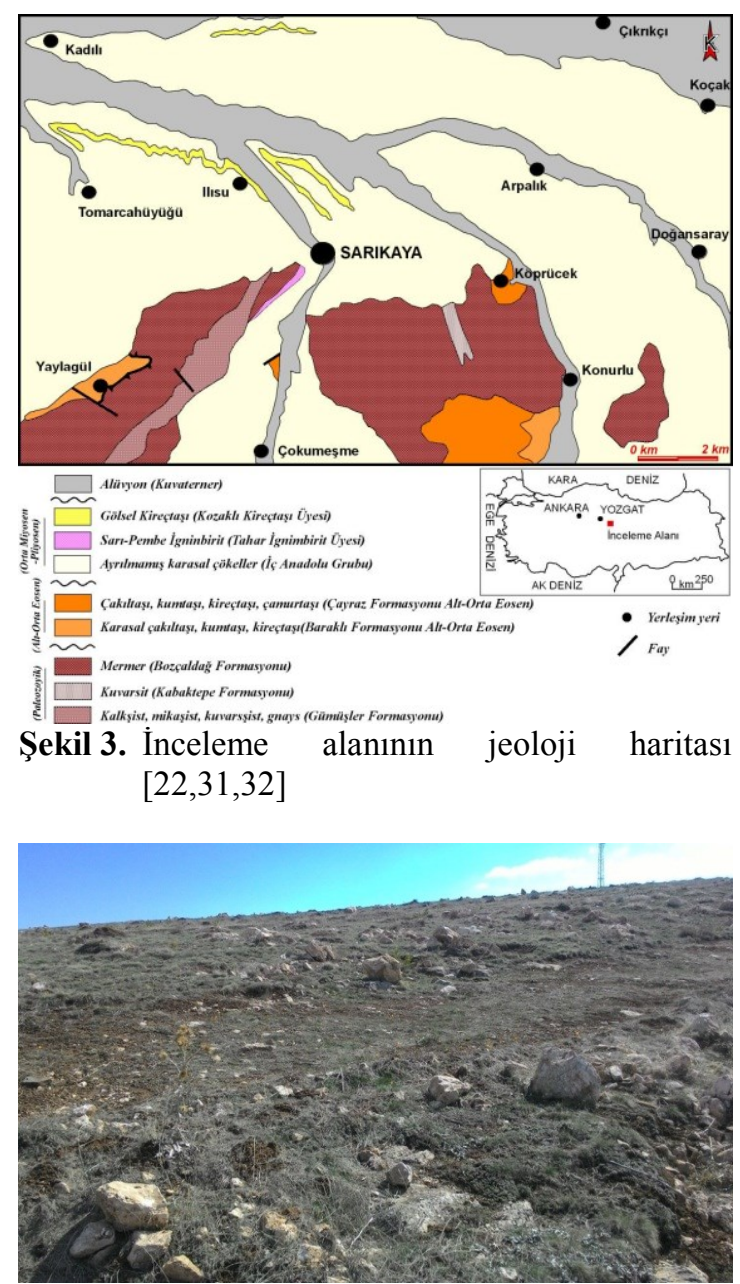

Şekil 4a. Bozçaldağ formasyonuna ait mermerler 


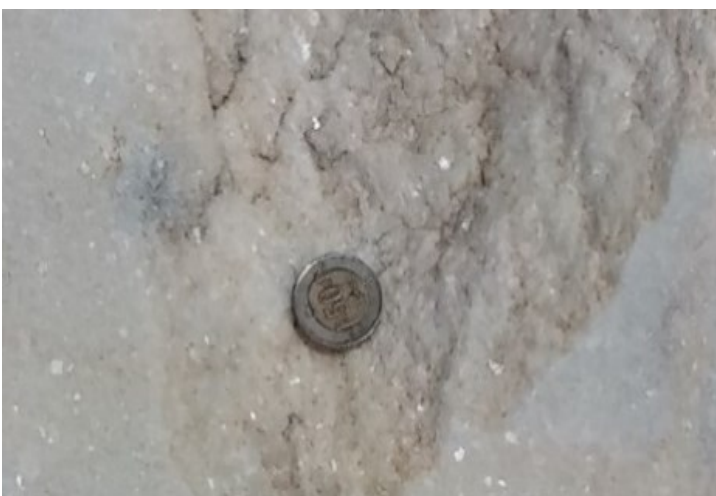

Şekil 4b. Bozçaldağ Formasyonuna ait iri kristalli mermerler (Yakın görünüm)

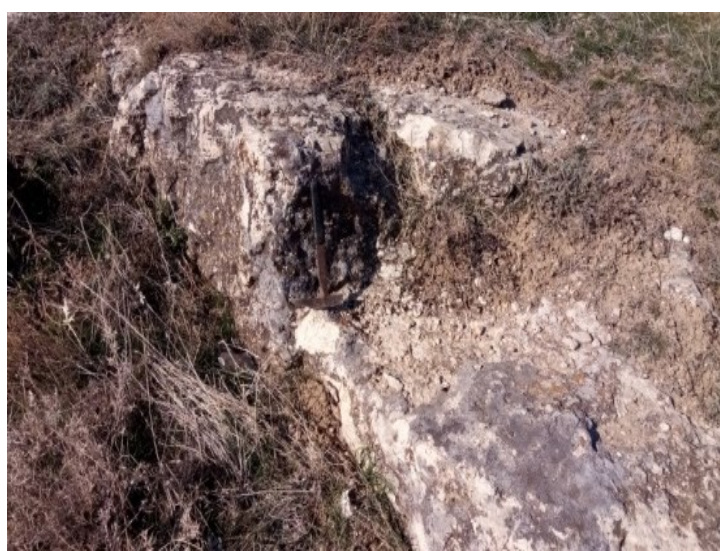

Şekil 5a. Kozaklı Kireçtaşı Üyesindeki beyaz renkli gözenekli kireçtaşı seviyeleri

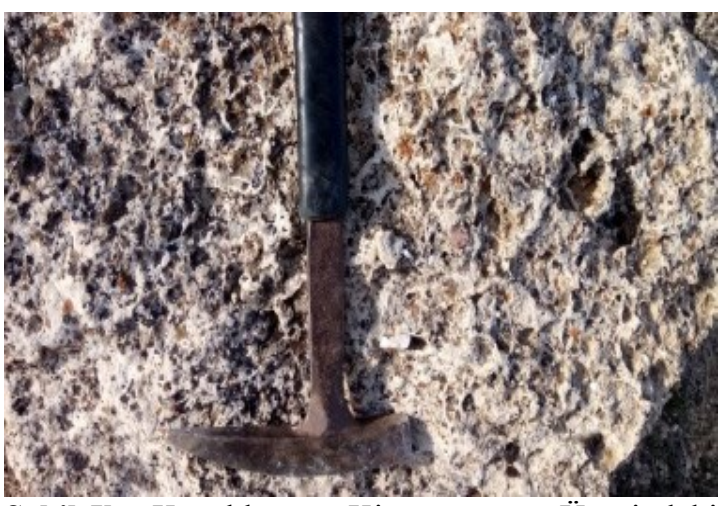

Sekil 5b. Kozaklı Kireçtaşı

Üyesindeki kırmızımsı kahverengi metamorfik kaya parçacıkları içeren beyaz renkli gözenekli kireçtaşı seviyeleri (Yakın görünüm)

\section{HAMAM \\ YAPIMINDA KULLANILAN DOĞAL YAPI TAŞLARI}

Termal Roma Hamamı'nın cephe ve havuzlarında beyaz renkli orta-iri kristalli, yer yer breșik dokuya sahip mermerler kullanılmıştır (Şekil 6a, 6b ve Şekil 7). Hamam taban döşemelerinde de altıgen olarak kesilmiş "opus sectile" olarak adlandırılan taban döşemesi bulunmaktadır [22] (Şekil 8).

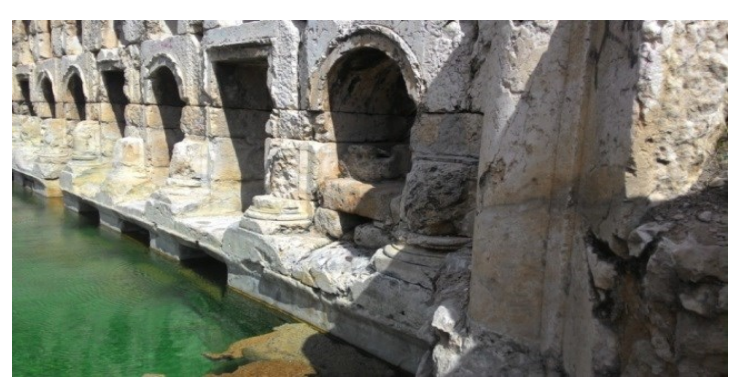

Şekil 6a. Sarıkaya Termal Roma Hamamı'nın mermerden yapılmış büyük havuz ve batı cephenin dıştan görünümü [22]
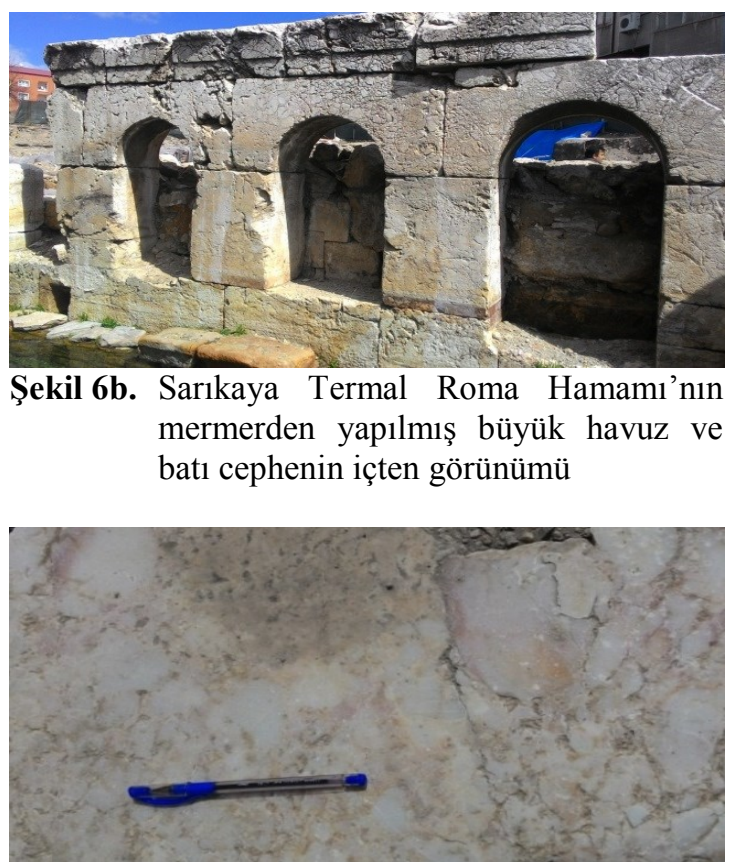

Şekil 7. Sarıkaya Termal Roma Hamamı'nın dış duvarında kullanılan breşik dokulu iri kristalli mermer 


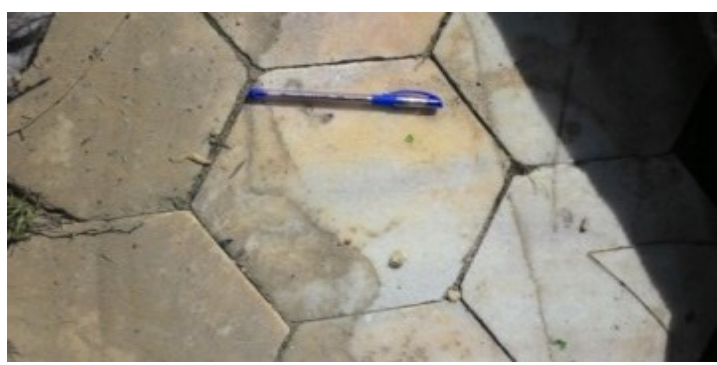

Şekil 8. Sarıkaya Hamamı'nın mermer taban döşemesi (opus sectile)

Termal hamamın iç kısım duvarlarında, kanallarda ve toprak altında kalan temel yapıda genellikle metamorfik kayaç kökenli kum-çakıl boyu kırıntı içeren, gözenekli, kirli beyaz-bej renkli kireçtaşları kullanılmıştır (Şekil 9). Hamam içerindeki oluklarda ve havuz basamaklarında da kireçtaşları kullanılmıştır (Şekil 10-11). Gözenekli, kırmızımsı sarı renkli damarlı travertenler, Termal Roma Hamamı'nın taban 1sıtması için oluşturulmuş hypocaust kısmında suspensura amacıyla taş dikmeler olarak kullanılmıştır [22] (Şekil 12).

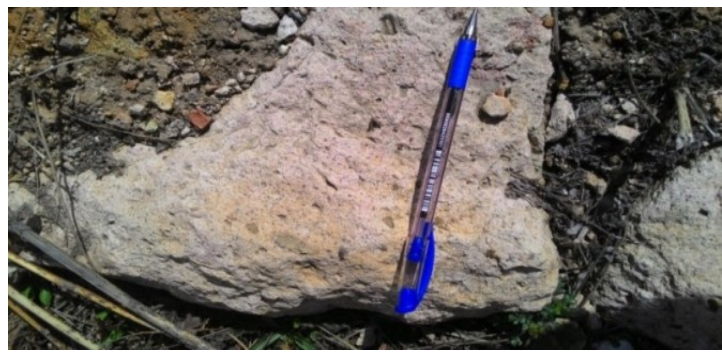

Şekil 9. Sarıkaya Termal Roma Hamamı'nın iç duvarları ve kanallarında kullanılan kireçtaş1

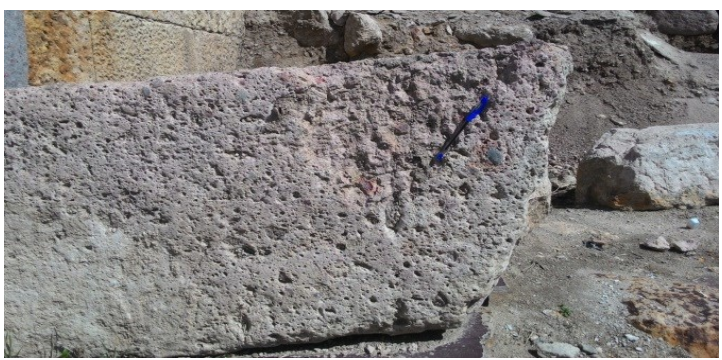

Şekil 10. Sarıkaya Termal Roma Hamamı içerisinde kırmızımsı kahverengi metamorfik kaya parçacıkları içeren kireçtaş1

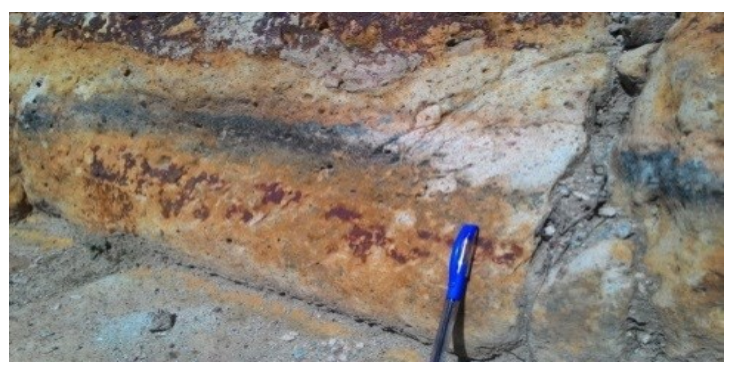

Şekil 11. Kaynağın ana çıkışındaki iç küçük havuz içi ve tabanı mermer, dış yükseltmeler sarımsı kahve renkli kireçtaş1

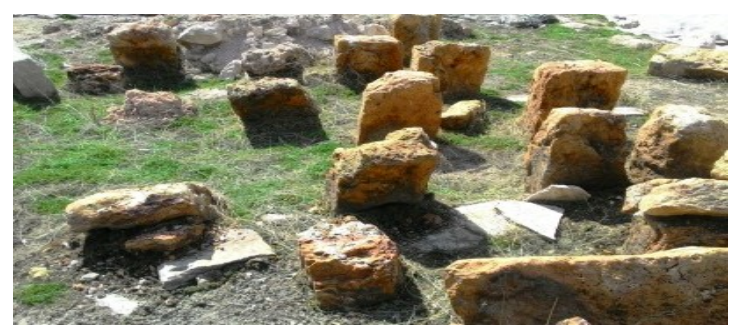

Şekil 12. Sarıkaya Termal Roma Hamamı taban 1sitmasında (hypocaust) kullanılan traverten dikmeler (supensura)

\section{DENEYSEL ÇALIŞMALAR}

Yozgat Sarkkaya bölgesinde araziden temin edilen mermer ve kireçtaşı numunelerinin fiziko-mekanik özelliklerinin belirlenmesi öncesinde numune hazırlama işlemleri gerçekleştirilmiştir. Numuneler TS EN ve ISRM standartlarında belirtilen numune boyutlarında Ahi Evran Üniversitesi Kaman Meslek Yüksekokulu, Madencilik ve Maden Çıkarma Bölümü Doğal Taş Analiz Laboratuvarında hazırlanmıştır (Şekil 13).

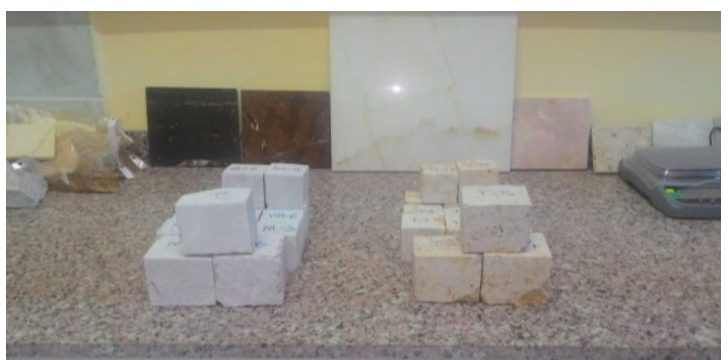

Şekil 13. Fiziko-mekanik deneyler için farklı ebatlarda hazırlanan numunelerin görünümü 
Araziden alınan numunelerin ağırlıkça su emme (ASE) (TS EN 13755) [26], birim hacim ağırlık (BHA), özgül ağırlık (ÖA), toplam porozite (TP) (TS EN 1936) [27], böhme yüzey aşınma (BYA) (TS EN 14157) [28], Shore sertlik (SH) (ISRM (1981) [29] ve tek eksenli basınç dayanımı (TEBD) (TS EN 1926) [30] gibi fiziksel ve mekanik özellikleri ilgili standartlara göre belirlenmiştir. Elde edilen veriler Çizelge 1'de verilmiştir.

Çizelge 1. Kireçtaşının fiziksel ve mekanik özellikleri

\begin{tabular}{|l|c|c|c|}
\hline & Ortalama & $\begin{array}{c}\text { Standart } \\
\text { sapma }\end{array}$ & $\begin{array}{c}\text { Deney } \\
\text { sayısı }\end{array}$ \\
\hline ÖA & 2,71 & 0,0006 & 3 \\
\hline BHA $\left(\mathrm{gr} / \mathrm{cm}^{3}\right)$ & 2,41 & 0,06 & 10 \\
\hline ASE $(\%)$ & 3,24 & 0,53 & 10 \\
\hline TP $(\%)$ & 10,77 & 0,23 & 10 \\
\hline BYA $\left(\mathrm{cm}^{3} / 50 \mathrm{~cm}^{2}\right)$ & 31,48 & 2,12 & 3 \\
\hline SH & 39,47 & 4,15 & 40 \\
\hline TEBD $(\mathrm{MPa})$ & 49,98 & 10,75 & 10 \\
\hline
\end{tabular}

Çizelge 2. Mermerin fiziksel ve mekanik özellikleri

\begin{tabular}{|l|c|c|c|}
\hline & Ortalama & $\begin{array}{c}\text { Standart } \\
\text { sapma }\end{array}$ & $\begin{array}{c}\text { Deney } \\
\text { sayısı }\end{array}$ \\
\hline ÖA & 2,73 & 0,0005 & 3 \\
\hline BHA $\left(\mathrm{gr} / \mathrm{cm}^{3}\right)$ & 2,69 & 0,09 & 10 \\
\hline ASE $(\%)$ & 0,10 & 0,05 & 10 \\
\hline TP $(\%)$ & 1,14 & 0,15 & 10 \\
\hline BYA $\left(\mathrm{cm}^{3} / 50 \mathrm{~cm}^{2}\right)$ & 21,3 & 3,52 & 3 \\
\hline SH & 52,66 & 3,48 & 40 \\
\hline TEBD $(\mathrm{MPa})$ & 75,98 & 14,78 & 10 \\
\hline
\end{tabular}

Çizelge 1 ve 2'de gösterilen veriler neticesinde mermerin birim hacim ağırlığının kireçtaşına göre daha yüksek olduğu, porozite değerinin ise düşük olduğu belirlenmiştir. Ayrıca mermerin, kireçtaşına göre yüksek sertliğine bağlı olarak basınç dayanımının yüksek, aşınma dayanımın ise düşük olduğu belirlenmiştir.

Mermerin, porozite değerinin kireçtaşına göre düşük olmasına bağlı olarak kayaç su emme değerinin de daha düşük olduğu gözlenmiştir. Hamam bölgesinde karasal iklimin hüküm sürdüğü göz önüne alındığında, hamamda kullanılan doğal taşların atmosferik şartlarından etkilenmeleri beklenen bir durumdur. Kireçtaşlarında su emme değerinin yüksek olmasına bağılı olarak atmosferik şartlara maruz kalma ile gerçekleşen donma ve çözünme olayları sonucunda, kayaç dayanımında azalma ve aşınma değerinde ise artış meydana gelmiştir. MS 3. yy. ile MS 10 yy. arasında yazılı belgelerde adı geçen hamamın [21] hangi şartlar altında kullanımının sonlandığ dışında kalan kısımların ne şekilde tahrip olduğu bilinmemekle birlikte muhtemelen yıkılan taşların civardaki yapılarda devşirme olarak kullanıldığı düşünülebilir. Hamamın mevcut yapısı incelendiğinde, mermerden inşa edilen batı cephesinin ayakta kaldığı ancak iç ve diğer dış duvarlarda kullanılan kireçtaşlarının ise (mermere göre düşük basınç dayanımı ve sertlik ile yüksek aşınma ve porozite değerine bağlı olarak atmosferik şartlara karşı direnç gösterememesi nedeni ile) aşırı deformasyona uğradığı ve sadece toprak tarafindan örtülen temel sevilerinde günümüze kadar ulaşabildiği gözlenmiştir.

\section{SONUÇ}

Roma dönemlerindeki diğer yapılarda olduğu gibi Sarıkaya Termal Roma Hamamı'nda da doğal yapı taşları, hem bir yapı malzemesi hem de özellikle batı cephesinde gözlenen taş işlemeciliği ile bir süsleme malzemesi olarak kullanılmıştır. Yapı ve süsleme malzemelerinin seçimlerinde genellikle inşa edilecek yapıya yakın bölgedeki doğaltaşların seçildiği gözlenmektedir. Bunun nedeninin özellikle Roma Dönemi'nde ocaktan taş çıkarılması ve taşınmasında yakın kaynakların seçilme önceliğinin olduğu düşünülebilir [33]. Sarıkaya Termal Roma Hamamı'nın inşaat yerinin seçiminde temel belirleyici unsur şifalı su kaynağının yeri iken, ikinci öncelik ise büyük olasılıkla hammadde kaynağının konumudur.

Sarıkaya Termal Roma Hamamı'nın ana yapısını oluşturan mermerler, ilçenin birkaç kilometre güneyinde mostra veren masif görünümlü birbirini kesen kırık çatlak düzlemleri içeren, orta-iri kristalli mermerlerden oluşan Bozçaldağ Formasyonundan alınmıştır. Hamamın temelinde, iç-dış duvarlarında ve kanallarında kullanılan kumlu-çakıllı kireçtaşları ilçenin birkaç kilometre 
kuzeyinde bulunan gözenekli, genellikle metamorfik kökenli kum-çakıl boyu kırıntı içeren, yaklaşık 5 metre kalınlığa kadar ulaşan, kirli beyaz-sarımsı renkli, kumlu-çakıllı gölsel kireçtaşlarından oluşan Kozaklı Kireçtaşı Üyesinden alınmıştır. Taban 1sıtması için oluşturulmuş hypocaust kısmında ise suspensura amacıyla uygulanan travertenden oluşan taş dikmelerin, hamamın inşası sırasında tabandan sökülen ve dayanımı mermer ve kireçtaşına göre daha düşük olduğu düşünülen, sicak suyun çıkışında meydana gelmiş travertenlerden alındığ 1 düşünülmektedir. Genellikle tuğla örgü şeklinde uygulanan dikmelerde (suspensera) traverten kullanılmasının, iç ve batı cephesi haricindeki dış duvarlar, kanallar ve temelde kireçtaşı kullanılmasının nedeninin, maliyetin düşürülmesi, işlenme kolaylığı, 1sı yalıtımı özelliği gibi gerekçeler olabileceği düşünülmektedir. İç kısımda sıcak su kaynağının çıktığı alandaki havuzun kenar kısmı kireçtaşından yapılmıştır. Bu kireçtaşları içerisinde kum boyutunda farklı sertliğe sahip (kuvarsit, şist vb.) taneler içermesi ve aynı zamanda gözenekli bir dokuya sahip olması nedeni ile yıllar boyu kullanılmasına rağmen içerisinde aşınmaya karşı farklı direnç gösteren bölümlerin bulunması nedeni ile pürüzlülüğünü korumaktadır. Mermer ise homojen bir yapıya sahip olduğu için aşınma her bölgesinde benzer olacağından başta pürüzlü bir yüzey oluşturulsa da, y1llar içerisinde aşınma nedeni ile pürüzsüz bir yüzey alanına dönüşecektir. $\mathrm{Bu}$ nedenle havuz kenarı ve basamaklarında kayma ve düşmeleri önlemek amacıyla kireçtaşı kullanıldığı düşünülmektedir [22].

Yozgat Sarıkaya Termal Hamamı'nın bir sonraki nesillere aktarılması için, ilerleyen zamanlarda olası bir restorasyon çalışması yapılırken kullanılacak doğaltaşların doğru kaynaklardan seçilmesi noktasında, araştırmacılar tarafindan bu ve benzeri çalışmaların ortaya konması ile doğru restorasyon yapılmasında önemli veriler sağlanacağı şüphesizdir. Avrupa ve Ortadoğu'daki birçok antik yerleşimde mermer ve kireçtaşının ana yapı malzemesi olarak kullanıldığ 1 bilinmektedir [34] ve restorasyon sirasinda orijinal hammadde kullanılması önem arz etmektedir. Zira onarım sonrası yap1 taşlarının dış görünüm dışında atmosferik şartlara karşı dayanım ve yüzey aşınımına benzer tepki vermesi de gerekmektedir [19].

Arkeolojik varlıkların onarım ve korunması, bunların insanlığın ortak kültür mirası olması ve kendi topraklarında bulunan ülkelerce sahiplenilmesi gerekliliğinin yanı sıra kültürel turizm açısından değerlendirildiğinde onarım amaciyla ortaya konulacak maliyetin kendisini telafi edebilecek bir yapısı olduğu da gözden kaçırılmamalıdır. Günümüzde kültürel amaçlı seyahat eden turistlerin, arkeolojik varlıklara olan ilgilerinin daha yüksek düzeyde olduğu ve insanları kültürel turizm amaçlı seyahat etmeye teşvik eden unsurlar arasında tarihi eserler, ören yerleri, yöreye ait geleneksel yiyecek içecek çeşitliliği, kutsal değerler olduğu belirtilmiştir [35]. Sarıkaya Termal Roma Hamamı'nın da uygun malzeme ve teknikler kullanılarak restore edilmesi ve turizme kazandirılması durumunda kentin turizm potansiyeline olumlu katkı yapması muhtemeldir.

\section{KAYNAKLAR}

1. Ekincioğlu G., Başıüyük Z., Ekdur E., Ballı F., Kanbir E.S., 2014. Kırşehir Doğal Taş Sektör Analizi ve Yatırım İmkânları Raporu, Kırşehir Sanayi ve Ticaret Odası.

2. Andrefsky, W., 1998. Lithics, Cambridge University Press.

3. Andrefsky, W., 2008. Lithic Technology: Measures of Production, Use and Curation, Cambridge: Cambridge University Press, p. 340.

4. Eren, M.I., Prendergast, M.E., 2008. Comparing and Synthesizing Unifacial Stone Tool Reduction Indices. Lithic Technology: Measures of Production, Use and Curation, Cambridge University Press, Cambridge, 49-85.

5. Gölbaş, A., 2016. Türk Arkeolojisinin Kuramı, The Journal of International Social Research, 9 (46), 302-316.

6. Gamble, C., 2015. Archaeology: the Basics. Routledge. 
7. Salmon, M., 2008. Philosophy of Archaeology, Encyclopedia of Archaeology, Deborah M. Pearsall, 2, 1812-1818.

8. Taşlıgil, N., Şahin, G., 2016. Yapı Malzemesi Olarak Kullanılan Türkiye Doğal Taşlarının İktisadi Coğrafya Odağında Analizi, Marmara Coğrafya Dergisi, 33, 607-640.

9. Özdoğan, M., 2015. Hammadde Olarak Taş ve Kayaçlara Genel Bir Bakış, IV. ODTÜ Arkeometri Çalıştayı Bildiriler Kitabı, s.27-34.

10. Balkan-Atlı, N., Binder, D., Cauvin, M.C., 1999. Obsidian: Sources, Workshops and Trade in Central Anatolia. Neolithic in Turkey: the Cradle of Civilization. Oxbow Books, Oxford, s.133-145.

11. Michailidou, A., Dogan, I.B., 2008. Trading in Prehistory and Protohistory: Perspectives from the Eastern Aegean and Beyond. Sailing in the Aegean: Readings on the Economy and Trade Routes, s.17-53.

12. Gölbaş, A., Başıüyük, Z., 2012. Anadolu Kültür Oluşumunda Tuzun Rolü, Batman Üniversitesi İnsani Bilimler Dergisi, 1(1), 45-54.

13. Kramer, S.N., Wolkstein, D., 1983. Inanna, Queen of Heaven and Earth: Her Stories and Hymns from Sumer. Rider.

14. Farrelly, L., 2017. The Fundamentals of Architecture. Bloomsbury Publishing.

15. Price, C.A., Doehne, E., 2011. Stone Conservation: an Overview of Current Research. Getty Publications.

16. Kazanc1, N., Gürbüz, A., 2014. Jeolojik Miras Nitelikli Türkiye Doğal Taşları. Geological Bulletin of Turkey, 57(1), 19-44.

17. International Charter for the Conservation and Restoration of Monuments And Sites (The Venice Charter, 1964), II. International Congress of Architects and Technicians of Historic Monuments, Venice.

18. Altunel, E., 2012. Kültürel Jeoloji: Jeoloji’nin İnsanoğlunun Yaşamı Üzerindeki Etkileri. Kuvaterner Bilimi (Ed.: Kazanc1, N. ve Gürbüz, A.), Ankara: Ankara Üniversitesi Yayınları, (350), 195-214.

19. Siegesmund, S., Weiß, T., Vollbrecht, A., 2002. Natural Stone, Weathering Phenomena, Conservation Strategies and Case Studies:
Introduction. Geological Society, London, Special Publications, 205(1), 1-7.

20.T.C. Kültür ve Turizm Bakanlığı Yozgat İl Kültür ve Turizm Müdürlüğü, Sarıkaya Roma Hamamı, http://www.yozgatkulturturizm.gov. tr/TR,92801/sarikaya-roma-hamami.html.

Erişim tarihi: Ocak 25, 2018.

21. Şenyurt, H.K., 2016. Sarıkaya Roma Hamamı Tarihçesi Ve 2010-2015 Yılı Kazı Çalışmaları Sonuçları, I. Uluslararası Bozok Sempozyumu 05-07 Mayıs 2016 Bildiri Kitabı, (Ed.) Kadir Özköse, 1, 110-121.

22. Önal, M.M., Başıbüyük, Z., Gölbaş, A., 2017. Antik Sarıkaya Termal Roma Hamamının Mimarisi ve Yapımında Kullanılan Doğal Yap1 Taşları (Sarıkaya-YOZGAT), II. Uluslararası Bozok Sempozyumu: Yozgat'ın Turizm Potansiyelleri ve Sorunları Bildiriler Kitabı, 1, 19-33.

23. Von der Osten, H.H., Schmidt, E.F., Newell, E. T., 1937. The Alishar Hüyük. (Vol. 30). The University of Chicago Press.

24. Fagan, G., 1999. Bathing in Public in the Roman World, Londra.

25. Baykan, D., 2012. Roma Dönemi Tedavi Mekânları, İsmail Fazlığlu Anı Kitabı, (Ed.) Işık Şahin, s.43-49.

26.TS EN 13755, 2003. Doğal Taşlar-Deney Metodlari-Atmosfer Basincinda $\mathrm{Su}$ Emme Tayini. Türk Standartları Enstitüsü, Ankara.

27.TS EN 1936, 2006. Doğal Taşlar-Deney Yöntemleri-Gerçek Yoğunluk, Görünür Yoğunluk, Toplam ve Açık Gözeneklilik Tayini. Türk Standartları Enstitüsü, Ankara.

28.TS EN 14157, 2005. Doğal Taş-Aşınma Direncinin Tayini. Türk Standartları Enstitüsü, Ankara.

29.ISRM, 1981. Rock Characterization, Testing and Monitoring-ISRM Suggested Methods. Brown, E.T. (ed), Pergamon Pres, p.211.

30.TS EN 1926, 2000. Doğal Taşlar-Deney Metodları-Basınç Dayanım Tayini. Türk Standartları Enstitüsü, Ankara.

31. Dönmez, M., Akçay, A.E., Kara, H., Yergök, A.F., Esentürk, K., 2005. 1:100.000 ölçekli Türkiye Jeoloji Haritaları, Yozgat J 34 Paftası No: 48, Maden Tetkik ve Arama Genel Müdürlüğü, Ankara s.13. 
32. Akçay, A.E., Dönmez, M., A.E., Kara, H., Yergök, A.F., Esentürk, K., 2008. 1:100.000 Ölçekli Türkiye Jeoloji Haritaları, Yozgat İ 34 paftası No: 81, Maden Tetkik ve Arama Genel Müdürlüğü, Ankara s.13.

33. Bingöl, O., 2004. Arkeolojik Mimari’de Taş, Homer Kitabevi.

34. Dan, M.B., Pøikryl, R., Török, Á., 2009. Materials, Technologies and Practice in Historic Heritage Structures. Springer Science \& Business Media.

35. Gölbaş, A., Atak, O., 2016. Arkeolojik Potansiyelin Kırsal Turizme Kazandırılması: Ortaca Örneği. The Journal of International Social Research, 9(47), 1210-1223. 
